\title{
NOTES ON THE DISTRIBUTION AND SYSTEMATICS OF MYOTIS MYSTACINUS KUHL, 1819
}

\author{
by
}

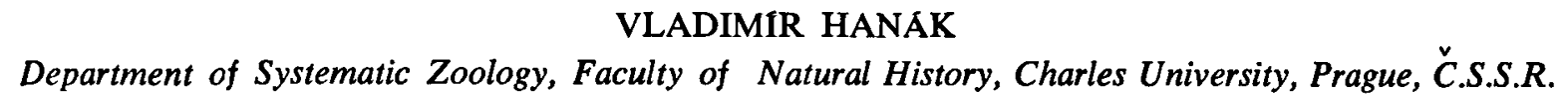

In $1965 \mathrm{I}$ recorded the occurrence of two distinct forms of Myotis mystacinus in Central Europe; my preliminary ranking was that they were two subspecies, Myotis mystacinus mystacinus and Myotis mystacinus brandtii. Those findings were in agreement with previous information by Topál (1958) pointing out differences in the morphology of the baculum in Hungarian populations of that species, and even considering the differences between the two forms of specific value. The present paper is a summary of new discoveries concerning this problem; the characters distinguishing the two forms are discussed, whereas new information on their distribution in Central Europe is presented, and their systematic position is evaluated.

\section{DISTINGUISHING CHARACTERS BETWEEN THE TWO FORMS}

Baculum. - The differences in the shape and size of baculum have already been described in detail by Topál (1958), as supplemented by Hanák (1965) based on Czechoslovak material. More detailed data have been obtained by a later study of 11 specimens of $M . m$. mystacinus and 8 specimens of $M . m$. brandtii from Bohemia and Slovakia. The baculum of $M . m$. mystacinus is minute, its shape resembles the baculum of young specimens of $M$. myotis. In dorsal view its outline is approximately oval, projections at the proximal end are missing. The saddle shape, characteristic of the Myotis species (Topál, 1958), is only slightly indicated in some individuals by an obsolete medial ridge on the dorsal side (fig. $1 \mathrm{~A}$ ). The whole profile of the baculum is concave, the ventral depression is moderately indicated in some specimens only. Its length ranges from 0.43 to $0.62 \mathrm{~mm}$ (mean $0.49 \mathrm{~mm}$ ), its width from 0.22 to $0.29 \mathrm{~mm}$ (mean $0.26 \mathrm{~mm}$ ).
The baculum of $M . m$. brandtii is markedly bigger, typically saddle-shaped. The medial ridge on the dorsal side, forming a protuberance in the proximal part, is characteristic. On the ventral side there is a distinct depression, the sulcus urethralis (fig. 1 C, D). Measurements: length $0.81-0.97$ $\mathrm{mm}$ (mean $0.87 \mathrm{~mm}$ ), width $0.41-0.59 \mathrm{~mm}$ (mean $0.50 \mathrm{~mm}$ ). It appears that there are striking differences in the morphology of the baculum in the material from Czechoslovakia as well, although the size differences are less pronounced than those given by Topál (1958). On the whole we can say that the differences found between the two forms of $M$. mystacinus are larger than those between the other species of this genus.

Penis. - The differences in the shape of penis were pointed out in my previous paper (Hanák, 1965). The penis of M.m. mystacinus is smaller, evenly thick along its entire length (fig. $2 \mathrm{~A}$ ). The one of $M . m$. brandtii is more robust and markedly thicker in the region of glans penis (fig. $2 \mathrm{~B}$ ).

So far the differences in the morphology of the penis and baculum have been the most conspicuous distinguishing characters between mystacinus s.str. and brandtii. That is why we were interested in their variability during the postnatal development. The study of banded individuals at winter quarters in Slovakia has proved that the shape of the penis and of the baculum, characteristic for each of the two forms, does not change during 1 to 4 years after the banding. Of course, the baculum of adult specimens of both forms varies individually, as is shown in fig. 3 .

The shape of skull. - Apparently there are only minor differences in the general morphology of the skulls of both forms, except for their size. In lateral view the skulls of the mystacinus form seem to be more convex in the frontal region than the skulls of the brandtii form (fig. 4). 


\section{DISCUSSION AND CONCLUSIONS}

What I have observed concerning the foetal development taking place in the left horn only is exactly the reverse of what Asdell (1965) reports with respect of the same bat. The other horn does not appear to be in any way defective. It would be interesting to determine just why the foetal development should be confined to one uterine horn. Rapid growth is one feature of $H$. caffer that has been brought out above. The attainment of the adult forearm length in three months would suggest attainment of sexual maturity in the same length of time. But this does not appear to be the case since it is now clear that breeding in this bat does not start until December and is a seasonal breeder. Histological work to determine when ovulation and spermatogenesis commence in the newly born bats would appear necessary here.
The occurrence of young in March in $H$. caffer is very much after the pattern that has been observed elsewhere in the seasonal breeders of the tropics (see for instance, Mutere 1968). These births take place just before the onset of the peak rains. With these rains there is also a peak in the availability of such insect food as Lepidoptera (see Mutere, 1969). Thus it would appear that such an abundance of food brought about by increased rain is just what both the young and the adult bats that have just given birth need for survival. Rain in this case would be playing a proximate role while food (the insects) would be an ultimate factor in the breeding of $H$. caffer.

\section{ACKNOWLEDGEMENTS}

I wish to thank the field staff of the East African Virus Research Institute for collecting the bats for this study.

\section{REFERENCES}

ASDell, S. A., 1965. Patterns of mammalian reproduction, 2nd ed. (Constable).

BAKER, J. R., (1947). The seasons in a tropical rain-forest (New Hebrides), 7. Summary and general conclusions. J. Linn. Soc., (Zool). 41 (2) : 8.

Marshall, A.J. \& P.S. Corbet, 1959. The breeding biology of equatorial vertebrates. Reproduction of the bat Chaerephon hindei Thomas at latitude $0^{\circ} 26^{\prime} \mathrm{N}$. Proc. zool. Soc. London, 132 : 607-616.

Mutere, F. A., 1968. The breeding biology of the fruit bat, Rousettus aegyptiacus E. Geoffroy living at $0^{\circ}$ 22'5. Acta Tropica, 25 (2) : 112-211.

,- 1969 . Breeding cycles in tropical bats in Uganda, $\mathbf{J}$. Ecol., 56 (2) : 5-9; J. anim. Ecol., 37 (2) : 5-9; J. appl. Ecol., 5 (2) : 5-9. 